\title{
Microwave Synthesis of Titanium Silicalite-1 Using Solid Phase Precursors
}

\author{
K. Y. Kim, W. S. Ahn, ${ }^{\dagger}$ D. W. Park, J. H. Oh, ${ }^{\dagger}$ C. M. Lee, ${ }^{\dagger}$ and W. P. Tai ${ }^{\dagger}$ \\ School of Chemical Science and Engineering, \\ ${ }^{\dagger}$ School of Material Science and Engineering, Inha Lnwersitv, Incheon $402-751$, Korea \\ Received November t $_{1} 2003$
}

\begin{abstract}
Titanium silicalite-1 (TS-1) molecular sieve was produced by microwave heating of amorphous titaniumcontaining solid precursors after impregnation with aqueous $\mathrm{TPAOH}$ solution. $\mathrm{SiO}_{2}-\mathrm{TiO}_{2}$ xerogel. sub-nicron sized $\mathrm{SiO}_{2}-\mathrm{TiO}_{2}$ prepared by thermal plasma process, and Ti-containing mesoporous silica, Ti-HMS. were tested as the solid phase substrates. Highly cry stalline product was obtained within $30 \mathrm{~min}$. after microwave irradiation with yields over $90 \%$ using $\mathrm{SiO}_{2}-\mathrm{TiO}_{2}$ xerogel, which showed essentially identical phy sicochemical properties to TS-1 prepared by conventional hydrothermal method. Excellent catalytic activity was also obtained for 1-hexene epoxidation using $\mathrm{H}_{2} \mathrm{O}_{2}, \mathrm{SiO}_{2}-\mathrm{TiO}_{2}$ particles prepared by thermal plasma and Ti-HMS were found inferior as a substrate for TS-1, probably due to difficulties in wetting the surface uniformly with TPAOH
\end{abstract}

Key Words : TS-1. $\mathrm{SiO}_{2}-\mathrm{TiO}_{2}$ xerogel. Thermal plasma. Ti-HMS. Microwave heating

\section{Introduction}

Titanium silicalite-1 (TS-1) discovered by Enichem ${ }^{1}$ is a silica rich molecular sieve with MFI stnucture in which isolated titanium species in the zeolite framework function as catalytic sites for oxidation of variety of organic substrate using $\mathrm{H}_{2} \mathrm{O}_{2}$ as oxidant. TS- 1 is known to catalyze aromatic hydroxylation. alkene epoxidation. ketone ammoximation. alcohol and alkane oxidation. and ignited intense research activities on the preparation of diverse redox type molecular sieves in which transition metals such as Ti. V. Mn. Sn. or W are incorporated to the framework. Several reviews on the synthesis. characterization, and catalytic applications of TS1 were reported .-- $^{--4}$ but scientific investigations on the physicochemical properties of the catalytic material are still in active progress. $: 0$

Typically. TS-1 is synthesized in a relatively small scale by hydrothermal heating of the substrate mixture prepared by mixing liquid phase TEOS and a titanium alkoxide species in the presence of a structure directing agent. tetrapropylammonim hydroxide (TPAOH) 1-7 Days of hydrothernal heating at $4+3 \mathrm{~K}$ in an autoclave are usually necessary. However. alternative synthesis recipes are being sought in industrial applications such as in propylene epoxidation pursued at the moment for a larger scale TS-l production. These altennatives should be able to produce TS- $I$ in fast synthesis time with high solid yields without being compromised in catalytic performances.

Microwave heating of a clear liquid substrate mixture of TEOS. tetraethylorthotitanate (TEOT), and TPAOH was reported to produce TS-1 in substantially reduced crystallization time. ${ }^{7}$ Padovan ${ }^{8}$ and Uguina et $a .{ }^{9}{ }^{9}$ on the other hand. reported that TS-I using hydrothermal heating of $\mathrm{SiO}_{2}-\mathrm{TiO}_{2}$ xerogel impregnated with $\mathrm{TPAOH}$ resulted in enhanced

"Corresponding Author. e-mail: whasahniàinha.ac.kr crystal yield. Recently. advantages of these attempts were combined by us. demonstrating the feasibility' of making TS1 in high yields in significantly shortened crystallization time by microwave heating of the TPAOH impregnated $\mathrm{SiO}_{2}-\mathrm{TiO}_{2}$ xerogel. ${ }^{1 / 1}$ We also implemented this microwave heating of the mixed oxide xerogel precursors to prepare high quality niobium or tantalum incorporated silicalite-1. ${ }^{11}$ In this work. this microwave synthesis of TS-1 was extended to investigate the potential of using different solid phase titanium sources. $\mathrm{SiO}_{2}-\mathrm{TiO}_{2}$ xerogel, sub-micron sized $\mathrm{SiO}_{2}-$ $\mathrm{TiO}_{2}$ prepared by thermal plasma process. and Ti-containing mesoporous silica HMS (Ti-HMS) were tested for this purpose. A series of characterization work was performed to compare the physicochemical property of the TS-1 samples prepared.

\section{Experimental Section}

$\mathrm{SiO}_{2}-\mathrm{TiO}_{2}$ cogel was prepared via two-step acid/base solgel process by following the literature procedure of Uguina et $a .^{9}$ The mole ration of $\mathrm{Si} / \mathrm{Ti}$ was controlled to 50 . The gel obtained was dried ovenight at $383 \mathrm{~K}$ and subsequently ground to give a fine powder. $\mathrm{SiO}_{2}-\mathrm{TiO}_{2}$ sub-micron sized powder was prepared by thermal plasma process by injecting a pre-mixed $\mathrm{SiCl}_{4} / \mathrm{TiCl}_{4}(\mathrm{Si} / \mathrm{Ti}=50)$ liquid mixture through a metering valve to the Argon plasma flame. Oxygen was introduced at the top portion of the reaction tube. and the particles formed at the reaction tube wall. in collection vessel. and filter were collected for further use. Experimental set up is shown in Figure 1 and details of operation can be found in reference. ${ }^{1 ?}$

Ti-HMS was prepared following the synthesis protocol similar to the one reported by Zhong and Pinnavaia. ${ }^{13}$ The molar gel composition of the substrate mixture was $\mathrm{SiO}_{2}$ $0.02 \mathrm{TiO}_{2}: 0.2$ dodecylamine (DDA) : $9 \mathrm{EtOH}: 0.02 \mathrm{HCl}$ $160 \mathrm{H}_{2} \mathrm{O}$. Titanium isopropoxide (TIP) and TEOS were used 
as titanium and silica source, respectively, TEOS/TIP in ethanol solution was added to the solution of DDA in water and $\mathrm{HCl}$ under vigorous stirring and aged at ambient condition for $24 \mathrm{~h}$ to obtain the product. All samples were filtered, dried at room temperature, and calcined at $923 \mathrm{~K}$ for $4 \mathrm{~h}$.

Fach solid powder was dry impregnated by adding $1.6 \mathrm{~g}$ TPAOH (Aldrich $20 \%$ aclueous solution) per $1 \mathrm{~g}$ of each substrate. The impregnated substrate was transferred to a $200 \mathrm{~mL}$. Teflon autoclave for microwave heating. The microwave equipment used was a C.CM MDS-2100 model equipped with a fiber optic temperature and pressure controller as well as an adjustable power output (maximum $950 \mathrm{~W}$ at $2450 \mathrm{MHz}$ ). The sample was heated to $443 \mathrm{~K}$ for 0.5 to $2 \mathrm{~h}$. The sample was quickly heated to $443 \mathrm{~K}$ in $3 \mathrm{~min}$. using full power and subsequently adjusted to constant power of 500 $W$ to maintain the isothermal condition. The crystalline product was filtered, washed several times with distilled water, dried overnight at $383 \mathrm{~K}$, and calcined in air at $823 \mathrm{~K}$ for $5 \mathrm{~h}$,

The crystallinity of the samples prepared was measured by $\mathrm{X}$-ray diffraction using $\mathrm{Ni}$-filtered $\mathrm{CuK}_{\alpha}$ radiation (Philips, PW-1700), and the morphology of the samples were examined by ST:M (Hitachi, X-650). The specific surface areas and average pore diameters were measured by $\mathrm{N}_{2}$ adsorption using a Micromeritics ASAP 2000. FT-IR spectra were recorded in air at room temperature on a Bomem MB 104 spectrometer using a diffuse reflectance cell. UV-Vis diffuse reflectance spectroscopy was performed under ambient conditions using dehydrated $\mathrm{MgO}$ as a reference in the range of 190-800 nm on a Varian CARY 3F double beam spectrometer. The catalytic activities of all samples were tested for 1-hexene epoxidation using $\mathrm{H}_{2} \mathrm{O}_{2}$ as an oxidant. Reactions were carried out under vigorous stirring in a twoneck glass flask equipped with a condenser and a thermometer using $2.02 \mathrm{~g}$ of substrate, $150 \mathrm{mg}$ of catalyst. $25 \mathrm{ml}$. methanol as a solvent, and $0.65 \mathrm{~g}$ of $35 \mathrm{wt} \% \mathrm{H}_{2} \mathrm{O}_{2}$. The reaction was performed at $313 \mathrm{~K}$ for $2 \mathrm{~h}$ and the products were analyzed using a $\mathrm{GC}$ equipped with a SUPELCO fused silica capillary column and a FID.

\section{Results and Discussion}

Three kinds of titanium-containing solid precursors were employed to prepare $\mathrm{TS}-1$ by microwave heating after $\mathrm{IPAOH}$ impregnation on the samples. $\mathrm{SiO}_{2}-\mathrm{IiO}_{2}$ xerogel or commercial product of $5 \% \mathrm{SiO}_{2}-\mathrm{JiO}_{2}$ by Grace $\mathrm{Co}$. has been used before as a titanium source ${ }^{14}$ and these were claimed suitable as a starting material for $\mathrm{IS}-\mathrm{I}$. As an alternative, it was decided to test titaniumñcontaining mesoporus silica molecular sieve, $\mathrm{li}-\mathrm{HMS}$, and $\mathrm{SiO}_{2}-\left[\mathrm{iO}_{2}\right.$ powder prepared by thermal plasma process $\left(\mathrm{SiO}_{2}-\mathrm{liO}_{2}(\mathrm{P})\right)$ as precursors for ]S-l. The former could be synthesized easily at room temperature in the presence of a neutral amine surfactant and known to have substantially large surface area and pore volume with regular mesopores, which justify its use as a support material in many cases. '] he latter, on the other hand,

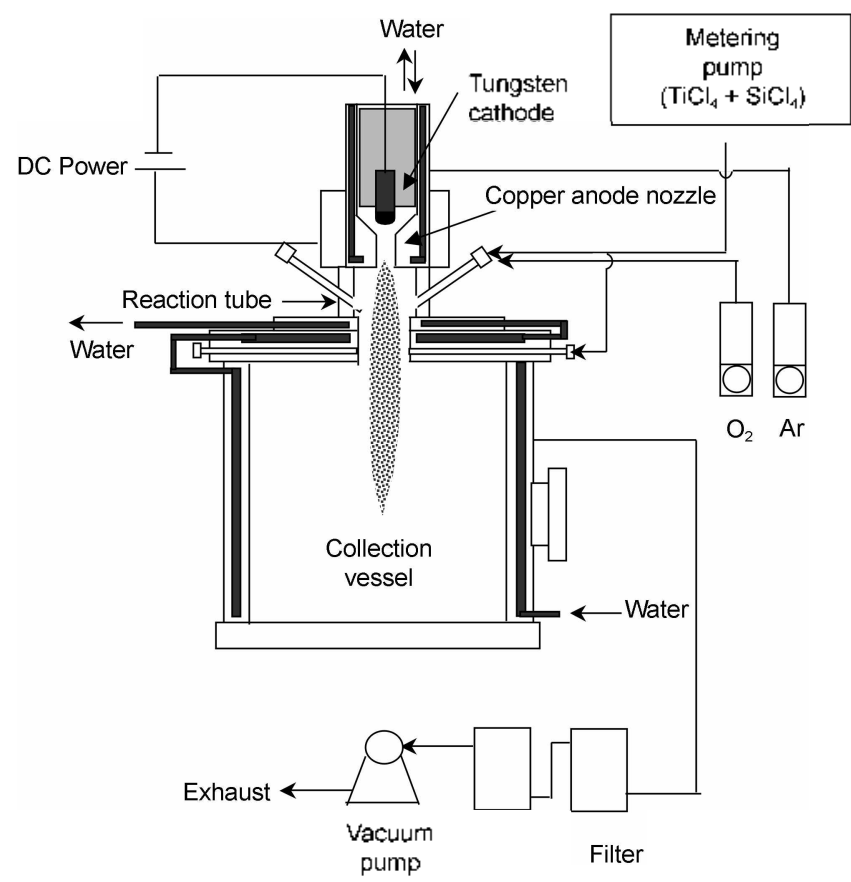

Figure 1. Schematic diagram of the thernal plasma apparatus for preparation of $\mathrm{SiO}_{2}-\mathrm{TiO}_{2}$ nanoparticles.

has a potential to be a good starting material on two different accounts; homogeneous distribution of titanium in silica matrix due to high synthesis temperature of the mixed oxide. and uniform sub-micron sized particles prepared from more economic $\mathrm{TiCl}_{4}$ and $\mathrm{SiCl}_{1}$ rather than respective alkoxide precursors.

Figure 2 shows the XRD patterns of the TS-1 samples prepared with these different solid phase titanium-containing precursors after microwave irradiation for $2 \mathrm{~h}$. One in conventional oven heating at $443 \mathrm{~K}$ for $24 \mathrm{~h}$ is also shown as a reference material. All TS-1 samples obtained after $2 \mathrm{~h}$ microwave irradiation showed characteristic peaks corre-

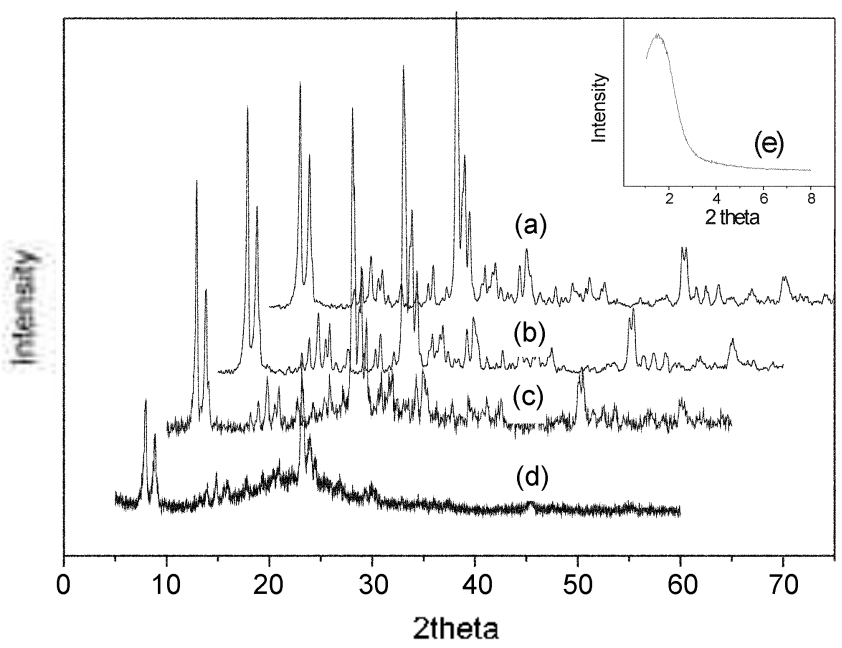

Figure 2. XRD spectra of (a) TS-1 (hydrothemal heating). (b) TS-

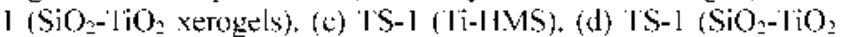
prepared by the themal plasma). (c) Ti-HMS. 
sponding to zeolite MFI structure. In particular, $\mathrm{SiO}_{2}-\mathrm{TiO}_{2}$ xerogel precursor showed virtually identical peak intensities to those of TS-1 prepared in conventional oven heating. Ti$\mathrm{HMS}$ and $\mathrm{SiO}_{2}-\mathrm{TiO}_{2}(\mathrm{P})$ were inferior as a precursor for TS1 as far as XRD qualities are concerned, which showed somewhat diminished peak intensities compare to that prepared with $\mathrm{SiO}_{2}-\mathrm{TiO}_{2}$ xerogel. In fact, $\mathrm{SiO}_{2}-\mathrm{TiO}_{2}(\mathrm{P})$ showed XRD pattern of only partially crystallized MFI structure. XRD pattern of mesoporous Ti-HMS was also shown in the Figure 1 which shows single intense peak near $2 \theta=1.8^{\circ}$ confirming its mesopore structure. The faster and more homogeneous heating achieved by microwave heating led to enhanced nucleation and crystal growth, and proved to be a significant advantage in the preparation of inorganic oxide materials. ${ }^{15}$ The crystal yield of TS-1 achieved by microwave heating of the TPAOH impregnated $\mathrm{SiO}_{2}-\mathrm{TiO}_{2}$ xerogel (b) was over $90 \%$ compared with the ca. $50 \%$ reported with the TS-1 prepared with liquid substrate mixture of silicon and titanium alkoxides."

SFM micrographs of the respective solid phase precursors and the corresponding TS-1 samples produced are shown in Figure 3. Uniform cubic-like particles with ca. $500 \mathrm{~nm}$ dimension were obtained from the irregular 1 to 7 micron large particles of $\mathrm{SiO}_{2}-\mathrm{TiO}_{2}$ xerogel. Fully-grown crystals were already apparent after $30 \mathrm{~min}$. microwave irradiation and crystals of virtually the same dimension were obtained after $2 \mathrm{~h}$ microwave heating. Spherical sub-micron size

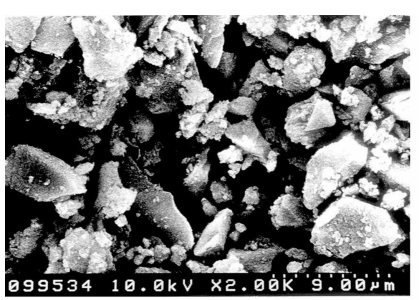

(a)

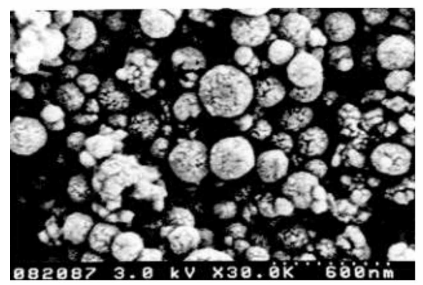

(c)

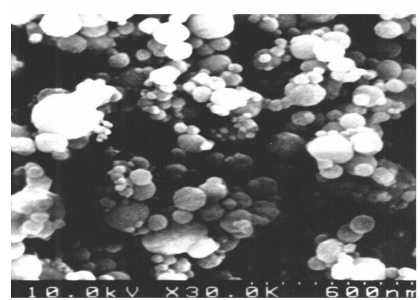

(e)

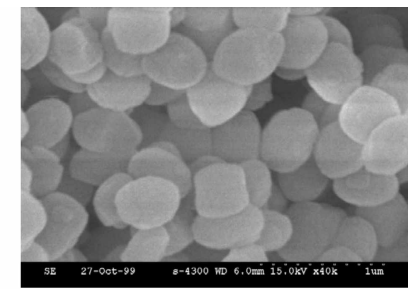

(b)

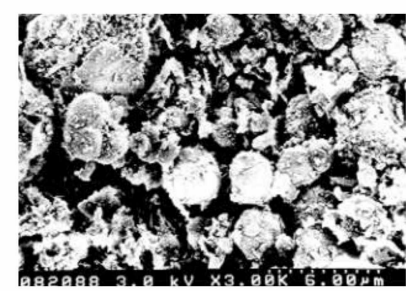

(d)

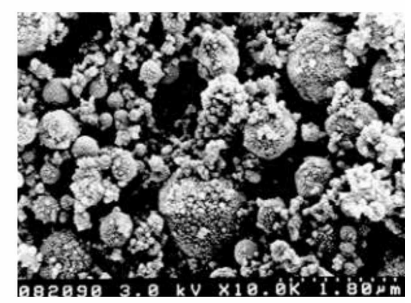

(f)
Figure 3. SEM micrographs of (a) $\mathrm{SiO}_{2}-\mathrm{TiO}_{2}$ xerogels. (b) $\mathrm{TS}-1$ (Microwave heating of $\mathrm{SiO}_{2}-\mathrm{TiO}_{2}$ xerogel). (c) Ti-HMS. (d) TS-1 (IIMS), (e) $\mathrm{SiO}_{2}-\mathrm{IiO}_{2}$ prepared by thermal plasma. (1) $\mathrm{IS}-\mathrm{I}$ ( $\mathrm{SiO}_{2}-$ $\mathrm{IiO}_{2}$ prepared by thermal plasma). particles for Ti-HMS and more uniform and smaller particles with spherical morphology for $\mathrm{SiO}_{2}-\mathrm{TiO}_{2}(\mathrm{P})$ were shown. However, TS-1 prepared by these precursors resulted in larger agglomerated mass with no morphological uniformity.

ВГ:T surface area of the precursors used were measured to be $701 \mathrm{~m}^{2} / \mathrm{g}$ for $\mathrm{SiO}_{2}-\mathrm{TiO}_{2}$ xerogel, $780 \mathrm{~m}^{2} / \mathrm{g}$ for Ti-HMS, and less than $5 \mathrm{~m}^{2} / \mathrm{g}$ for $\mathrm{SiO}_{2}-\mathrm{TiO}_{2}$ (P). $\mathrm{SiO}_{2}-\mathrm{TiO}_{2}$ (P) was virtually non-porous as observed by TEM (not shown) and highly dense with the smallest packing volume among the three precursors for the same weight of the solid precursors used for TPAOH impregnation. Bulk density was of $0.71 \mathrm{~g} /$ $\mathrm{cm}^{3}$. Apparently, these features are suspected to cause difficulty in infiltration of $\mathrm{TPAOH}$ into the $\mathrm{SiO}_{2}-\mathrm{TiO}_{2}$ core structure. Under such circumstances, dissolution of the solid phase would be hindered to some extent, which is believed to be involved in the mechanism of zeolite formation using microwave heating. i.e. formation of zeolite building blocks from the dissolved liquid phase. ${ }^{16}$ Ti-HMS, due to large surface area and mesopores were anticipated to be advantageous as a substrate, but proved otherwise. It seems two factors could have been acted against the expected performance. One, mesoporus materials prepared using surfactants as structure-directing agent are significantly more hydrophobic in nature than $\mathrm{SiO}_{2}-\mathrm{TiO}_{2}$ xerogels, ${ }^{17}$ which could make the introduction of the polar TPAOH inside the pores less effective. The other, Ti-HMS had low bulk density $(0.24$ $\left.\mathrm{cm}^{3} / \mathrm{g}\right)$ than $\mathrm{SiO}_{2}-\mathrm{TiO}_{2}$ xerogel with $0.52 \mathrm{~g} / \mathrm{cm}^{3}$, and was very voluminous for a given mass. As a result. it was difficult to wet the material unifornly with the given amount of TPAOH used in this work. This low bulk density is suspected to remain as a problem in many applications as a support for mesoporous materials.

Figure 4 shows IR spectra of the TS-1 samples and those

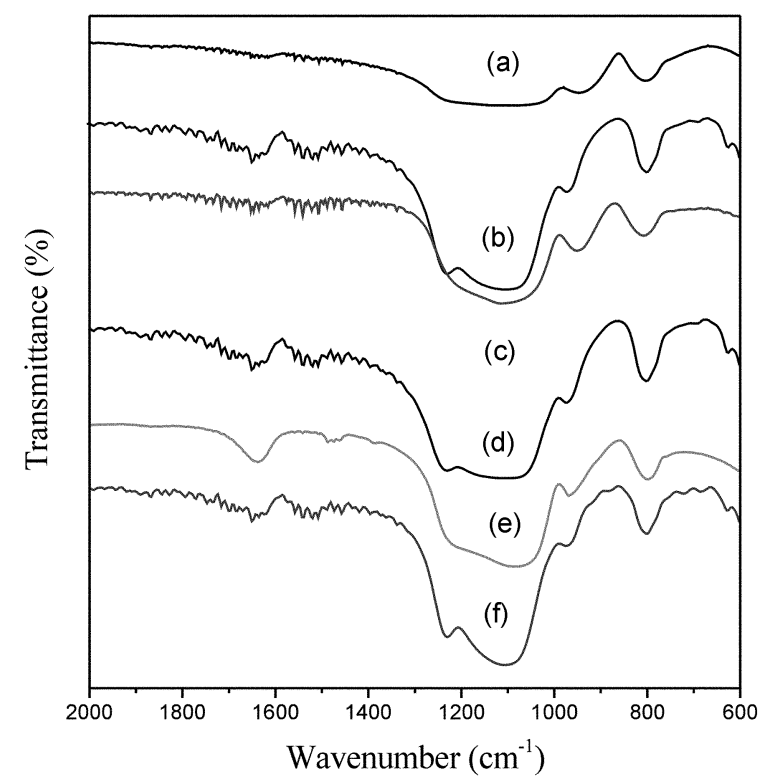

Figure 4. IR spectra of (a) $\mathrm{SiO}_{2}-\mathrm{liO} \mathrm{O}_{2}$ xerogels. (b) IS-I ( $\mathrm{SiO}-$ $\mathrm{TiO}_{2}$ xerogels). (c) $\mathrm{SiO}_{2}-\mathrm{TiO}_{2}$ prepared by thermal plasma. (d) $\mathrm{TS}-$ $1\left(\mathrm{SiO}_{2}-\mathrm{TiO}_{2}\right.$ prepared by the thermal plasma). (e) Ti-HMS. (I) TS1 (ji-IIMS). 


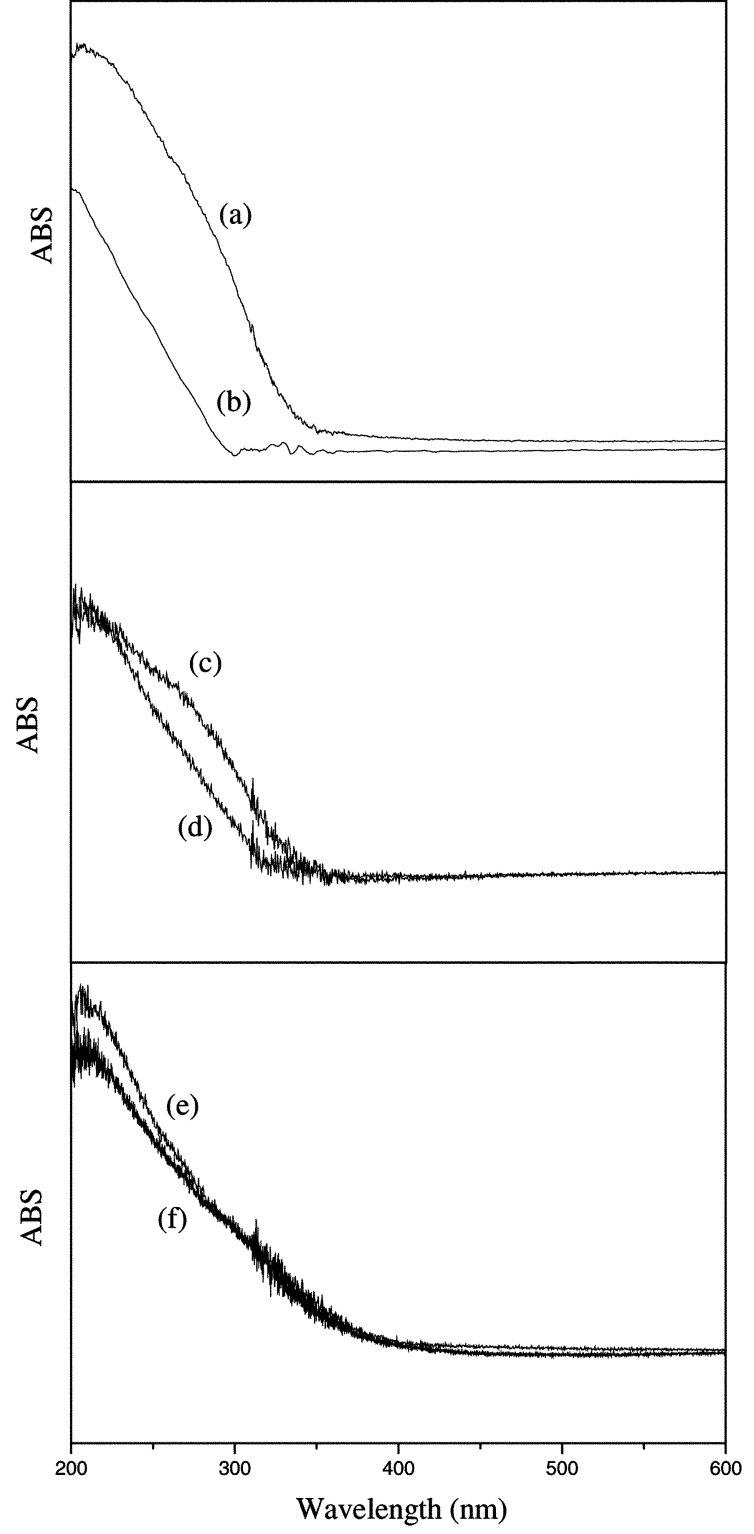

Figure 5, UV-Vis spectra of (a) $\mathrm{SiO}_{2}-\mathrm{IIO}_{2}$ xerogels. (b) $\mathrm{TS}-1$ ( $\mathrm{SiO}_{2}-\mathrm{THO} \mathrm{O}_{2}$ xerogels). (c) Tï-HMS. (d) IS-I (Ti-l IMS). (c) $\mathrm{SiO}_{2}-$ $\mathrm{TiO}_{2}$ prepared by thermal plasma. (t) $\mathrm{TS}-1\left(\mathrm{SiO}_{2}-\mathrm{TiO}_{2}\right.$ prepared by therma plasma).

of respective precursors. Characteristic IR band near 960 $\mathrm{cm}^{-1}$ corresponding to $\mathrm{Si}-\mathrm{O}-\mathrm{li}$ bond ${ }^{18}$ is observed for all the IS-] samples. The relative intensity of the $960 \mathrm{~cm}^{-1}$ to 800 $\mathrm{cm}^{-1}$ peak has often been used to estimate the titanium incorporation in TS-1 samples." Since IR spectra in this study have been obtained using hydrated samples, the characteristic IR band is slightly blue-shifted to $c a .971 \mathrm{~cm}^{-1}$ as reported earlier by Boccuti ef al. ${ }^{13}$ This peak was also observed for all the solid phase precursors, but at a slightly shifted position from TS-1 samples. Apparently, Ti-O-Si bond already exists in these solid precursors before structural transformation to zeolite is taking place. It was generally observed that the characteristic IR peak became somewhat narrower and refined after microwave heating, which is a consequence of Ti being incorporated to zeolytic structure.

Figure 5 compares UV-Vis spectra of the TS-1 samples and respective solid precursors. For titanium containing molecular sieves, an intense band at $c a .220 \mathrm{~nm}$ has been assigned to the ligand-to-metal charge transfer involving isolated $\mathrm{Ti}$ atoms in tetrahedral coordination. ${ }^{20}$ on which two water molecules may form part of the metal coordination sphere. The shoulder at $270 \mathrm{~nm}$ corresponds to partially polymerized hexa-coordinated Ti species, ${ }^{12}$ and a band at $370-410 \mathrm{~nm}$ corresponds to anatase plase. The spectra of $\mathrm{SiO}_{2}-\mathrm{TiO}_{2}$ xerogel (a) which is composed of both tetrahedral and octahedral titanium population went through drastic transition to TS-l(b) exhibiting a single narrow tetrahedral peak at $220 \mathrm{~nm}$. The spectra of Ti-HMS (c) shows broad absorption bands centered at 220 and 260-270 nm as reported by 7 hang of $a l^{13}$ The band at $c a .220 \mathrm{~mm}$ in Tisubstituted mesoporous materials may be associated with isolated Ti(IV) framework sites fundamentally similar in character to those in TS-1. Some Ti-O-Ti clusters are suspected to co-exist to some extent with the isolated Ti sites in Ti-HMS. Spectra (d) of the corresponding TS- 1 shows elimination of 260-270 $\mathrm{nm}$ peak, signaling more ordered arrangement of Ti-O-Si bond after microwave heating. No peaks corresponding to anatase phase at $330 \mathrm{~nm}$ was observed. $\mathrm{SiO}_{2}-\mathrm{TiO}_{2}(\mathrm{P})$ (e) showed very sharp $220 \mathrm{~nm}$ peak with little $270 \mathrm{~nm}$ shoulder, indicating the highest portion of $\mathrm{Ti}$ in tetrahedral arrangement among the three precursors used. TPAOH impregnation and subsequent microwave heating did not improve the spectrum much, due to difficulties in wetting the surface as mentioned above. These IR and UV-Vis spectral data indicate that favorable environment for titanium to take tetrahedral coordination in the subsequent hydrothermal treatment is already achieved in the solid phase precursors.

Table 1. Performance of I-hexene epoxidation reaction by various TS-1 cataly sts preprared

\begin{tabular}{|c|c|c|c|c|}
\hline \multirow{2}{*}{ IS-1 sample } & \multicolumn{2}{|c|}{$\mathrm{Si} / \mathrm{Ti}$} & \multirow{2}{*}{$\begin{array}{l}\text { 1-hexene } \\
\text { comversion }\end{array}$} & \multirow{2}{*}{$\begin{array}{l}\text { Product sclectivity } \\
\text { 1.2-Eposythexane }\end{array}$} \\
\hline & substrate & calcíted & & \\
\hline $\mathrm{IS}-1$ (nano-sizes $\mathrm{SiO}_{2}-\mathrm{LiO}_{2}$ prepared by thermal plasma) & 50 & 53 & 9 & $>99$ \\
\hline IS-1 (2\% Ti-IMMS) & 50 & 53 & 12 & $>99$ \\
\hline $\mathrm{IS}-1\left(\mathrm{SiO}_{2}-1 \mathrm{iO} \mathrm{O}_{2}\right.$ xerogels $)$ & 50 & 52 & 18 & $>99$ \\
\hline IS-1 (hydrothermal synthesis) & 40 & 42 & 21 & $>99$ \\
\hline IS-I (commercial product) & 40 & 42 & 20 & $>99$ \\
\hline
\end{tabular}

Reaction condition: $150 \mathrm{mg}$ catalyst. $2.02 \mathrm{~g}$ 1-hexente, $0.65 \mathrm{~g} 35 \% \mathrm{H}_{2} \mathrm{O}_{2}, 25 \mathrm{~mL}$ methanol ( $313 \mathrm{~K}$. teaction duration $2 \mathrm{~h}$ ). 
Finally. catalytic property of the TS-1 prepared by microwave heating of the solid titanium precursors were tested by 1-hexene epoxidation, and the results are summarized in Table 1. 1-Hexene conversions after $2 \mathrm{~h}$ reaction were in the decreasing order of TS-l $\left(\mathrm{SiO}_{2}-\mathrm{TiO}_{2}\right.$ xerogel $)>\mathrm{TS}-\mathrm{I}$ (TiHMS $)>$ TS-I $\left(\mathrm{SiO}_{2}-\mathrm{TiO}_{2}(\mathrm{P})\right)$ in accordance with the characterization results performed previously. Higher titanium contents in conmercial TS-1 sample and in TS-1 prepared by conventional hydrothermal heating led to higher conversions, but TS-1 prepared by microwave heating of the $\mathrm{SiO}_{2}$ $\mathrm{TiO}_{2}$ xerogel in accelerated crystallization had shown no detrimental effects in catalytic oxidation reactions conpared with these standard TS-1 cataly sts.

\section{Conclusions}

Microwave synthesis of TS- I was investigated using three different solid phase titanium sources of $\mathrm{SiO}_{2}-\mathrm{TiO}_{2}$ xerogel. sub-nicron $\mathrm{SiO}_{2}-\mathrm{TiO}_{2}$ powder prepared by thermal plasma process. and Ti-containing mesoporous silica HMS (TiHMS). Among these solid starting materials, $\mathrm{SiO}_{-}-\mathrm{TiO}_{2}$ xerogel proved superior to others as a TS-l precursor in terms of crystallinity, particle morphology. and catalytic activity in epoxidation. and demonstrated essentially identical physicochenical properties to the commercial sample prepared by using liquid phase precursors. Uniform wetting of the structure directing agent. TPAOH on the solid substrate was believed to be the governing factor leading to good catalyst. which was difficult to be materialized in Ti-HMS and sub-micron $\mathrm{SiO}_{2}-\mathrm{TiO}_{2}$ powder due to relatively hydrophobic surface and low bulk densities for the former, and nomporous low surface area with high density for the latter.

Acknowledgement. This work has been supported by grant KRF-2001-005-E00008 from Korean Research Foundation.

\section{References}

1. Taramasso. M.; Perego. G.: Notari, B. LS. Patent No. H10501. 1983.

2. Notari. B. Adh: Catal 1996. H. 253.

3. Vayssilov. G. N. Catal. Rev Sci. Eng 1997.39(3). 209.

4. Bellussi. G.: Rigutto. M. S. Stud Surf. Soi. Catal. 1994. 85.177

5. Bengoa. J. F.: Gallegos. N. G.: Marchetti. S. G.: Alvarez. A. M.: Cagnoli. M. V: Yeramian. A. A. Micropot Mesopor Hater: 1998. $2+.163$.

6. Lamberti. C.: Bordiga, S.: Zecehina A.; Carati, A.: Fitch. A. N.: Artioli. G.: Petrini. G.: Salvalaggio. M.: Marra. G. L. J. Catal. 1999. 183. 222

7. Uguina. M. A.: Serrano. D. P.: Sanz. R.: Castillo. E. Proceedings of the 12th IZC: Treacy: M. M. J.: Marcus, B. K: Bisher. M. E: Higgins. J. B., Eds.: Material Resarch Society: Pennsylvania, U. S. A. 1998: Vol. 3. p 1917.

8. Padovan. M.: Leofanti. G.: Rotia. P. Ew: Pat Appl. 311983. 1989.

9. Uguita. M. A.: Serrano. D. P.: Ovejero. G.: van Grieken. R.: Camacho. M. Appl Catal A: General 1995. 12+. 391.

10. Ahn. W. S.: Kang, K. K, Kim, K. Y. Catal Lett, $2001,72,229$

11. Ahn. W. S.; Kim. K. Y.: Kim. M. H.; Uh, Y. S. Stud Sutf Sci. Catal. $2001,135.242$.

12. Kong. T. K. Synthesis of TiO $\mathrm{O}_{2}$-based Nanoparticles by Themal Plasma. Masters Dissertation: Inha University: Incheotl. Korea. 20000.

13. Zhang. W: Froba. M: Wang, $\mathrm{J} ;$ Tanev, P. T.: Wong, J.: Pinnavaia. T. J.J. An. Chent Soc. 1996, J18.9164.

14. Padovan. M.: Leofanti, G.: Rofia. P. Eut Pat. Appl, 1989, 311. 983.

15. Gabriel. G.: Gabriel. S.: Grant. E. H.: Halstead. B. S. J.: Mingos. D. M. P. Chem. Soc. Rev 1998. 27.213.

16. Camblor. M. A.: Corma. A.: Martinez, A.: Perez-Pariente. J. $J$. Chent Soc. Chem. Commm 1992. 589.

17. Figueras, F.: Kochkar. H.; Caldarelli. S. Micopot Mesopot: Hater: 2000. 39. 249.

18. Bordiga. S.: Coluccia. S.: Lamberti. C.: Marchese. L.: Zecchina. A.: Boscherini. F.: Buffa. F.: Genonii. F.: Leofanti. G.: Petrini. G.: Vlaic. G. J. Phys. Chem. 1994. $98,4125$.

19. Boccuti. M. R,; Rao, K. M.: Zecchina, A.; Leofanti. G.: Petrini, G. Stud. Sinf Sci Catal. 1989. +8. 133.

20. Mantegazza. M. A.: Petrini. G.: Spano. G.: Bagatin. R.: Rivetti. F. J. Hol. Catal A 1999. 1 16. 223. 